\title{
SHR3824, a novel selective inhibitor of renal sodium glucose cotransporter 2 , exhibits antidiabetic efficacy in rodent models
}

\author{
Pang-ke YAN ${ }^{1}$, Li-na ZHANG ${ }^{1}$, Ying FENG ${ }^{1}$, Hui QU ${ }^{1}$, Li QIN ${ }^{1}$, Lian-shan ZHANG ${ }^{2}$, Ying LENG ${ }^{1, *}$ \\ ${ }^{1}$ State Key Laboratory of Drug Research, Shanghai Institute of Materia Medica, Chinese Academy of Sciences, Shanghai 201203, \\ China; ${ }^{2}$ Shanghai Hengrui Pharmaceuticals Co, Ltd, Shanghai 200245, China
}

\begin{abstract}
Aim: The sodium glucose cotransporter 2 (SGLT2) plays an important role in renal glucose reabsorption, thus serves as a new target for the treatment of diabetes. The purpose of this study was to evaluate SHR3824 as a novel selective SGLT2 inhibitor and to characterize its in vivo effects on glucose homeostasis. The effects of chronic administration of SHR3824 on peripheral insulin sensitivity and pancreatic $\beta$-cell function were also investigated.

Methods: The in vitro potency and selectivity of SHR3824 were assessed in HEK293 cells transfected with human SGLT2 or SGLT1. Acute and multi-dose studies were performed on ICR mice, GK rats and $d b / d b$ mice to assess the ability of SHR3824 to enhance urinary glucose excretion and improve blood glucose levels. 2-Deoxyglucose uptake and insulin immunohistochemical staining were performed in the soleus muscle and pancreas, respectively, of $d b / d b$ mice. A selective SGLT2 inhibitor BMS512148 (dapagliflozin) was taken as positive control.

Results: SHR3824 potently inhibited human SGLT2 in vitro, but exerted much weak inhibition on human SGLT1 (the IC S0 $_{\text {values of }}$ SHR3824 against human SGLT2 and SGLT1 were 2.38 and $4324 \mathrm{nmol} / \mathrm{L}$, respectively). Acute oral administration of SHR3824 (0.3, $1.0,3.0 \mathrm{mg} / \mathrm{kg}$ ) dose-dependently improved glucose tolerance in ICR mice, and reduced hyperglycemia by increasing urinary glucose excretion in GK rats and $d b / d b$ mice. Chronic oral administration of SHR3824 $\left(0.3,1.0,3.0 \mathrm{mg} \cdot \mathrm{kg}^{-1} \cdot \mathrm{d}^{-1}\right)$ dose-dependently reduced blood glucose and $\mathrm{HbA} 1 \mathrm{c}$ levels in GK rats and $d b / d b$ mice, and significantly increased insulin-stimulated glucose uptake in the soleus muscles and enhanced insulin staining in the islet cells of $d b / d b$ mice.

Conclusion: SHR3824 is a potent and selective SGLT2 inhibitor and exhibits antidiabetic efficacy in several rodent models, suggesting its potential as a new therapeutic agent for the treatment of type 2 diabetes.
\end{abstract}

Keywords: sodium glucose cotransporter 2 (SGLT2); SHR3824; dapagliflozin; type 2 diabetes mellitus; blood glucose; insulin sensitivity; $\beta$-cell function

Acta Pharmacologica Sinica (2014) 35: 613-624; doi: 10.1038/aps.2013.196

\section{Introduction}

Several national and regional studies have documented a rapid increase in the prevalence of diabetes in the Chinese adult population. The China National Diabetes and Metabolic Disorders Study, conducted from June 2007 through May 2008, recently indicated that diabetes has reached epidemic proportions in the general adult population in China. Overall, 92.4 million adults $\left(9.7 \%\right.$ of the adult population) have diabetes ${ }^{[1]}$. The rapid increase in the prevalence of diabetes and its serious complications, including cardiovascular diseases, renal failure (requiring dialysis or transplant), blindness and diabetic

\footnotetext{
* To whom correspondence should be addressed. E-mail yleng@mail.shcnc.ac.cn

Received 2013-11-20 Accepted 2013-12-30
}

neuropathy, have significantly jeopardized patient quality of life and have become a huge economic burden to Chinese society $^{[2]}$.

The kidneys play an important role in the regulation of plasma glucose levels by reabsorbing nearly the entire filtered load of glucose in the proximal tubule. Glucose reuptake in the proximal tubule is mediated by sodium-glucose cotransporters (SGLTs) ${ }^{[3]}$. Approximately $90 \%$ of the reabsorbed glucose in the kidney has been shown to occur in S1 segments of the proximal tubules, where the low-affinity, high-capacity SGLT2 resides. The remaining $10 \%$ is removed during passage of the filtrate through the S3 segment, where the highaffinity, low-capacity SGLT1 resides ${ }^{[4]}$. Although SGLT1 plays a minor role in renal glucose reabsorption, this co-transporter facilitates the absorption of dietary glucose in the intestine. 
Evidence for the deleterious effects of SGLT1 inhibition has been derived from individuals with mutations in the SGLT1 gene. These patients experience glucose-galactose malabsorption syndrome, which results in severe, sometimes fatal diarrhea ${ }^{[5]}$. Mutations in the SGLT2 gene result in renal glucosuria $^{[6]}$. These findings indicate that SGLT2 plays a dominant role in the control of glucose transport in the kidney and that the level of specificity for SGLT2 inhibition is an important consideration because SGLT1 inhibition is associated with potentially serious side effects.

The first SGLT inhibitor evaluated was phlorizin, which was isolated from the root bark of the apple tree. Phlorizin demonstrated antidiabetic potency, lowering plasma glucose levels and improving insulin resistance by increasing renal glucose excretion ${ }^{[7]}$. However, phlorizin was not developed as a drug for the treatment of diabetes because of its nonselective activity on both SGLT1 and SGLT2 and its metabolic instability in vivo ${ }^{[8]}$. Subsequently, several companies developed SGLT2 inhibitors that lacked the disadvantages of phlorizin, and some of these compounds have progressed to late stage clinical trials or are even available for clinical use ${ }^{[9-12]}$. One of the earliest selective SGLT2 inhibitors reported, dapagliflozin (formerly known as BMS512148), was shown to be a selective and orally effective SGLT2 inhibitor able to induce renal glucose excretion and reduce glucose excursions in normal and diabetic rats ${ }^{[13]}$.

Type 2 diabetes mellitus (T2DM) is characterized by insulin resistance and pancreatic $\beta$-cell dysfunction. The correction of hyperglycemia by the inhibition of SGLT2 is thought to improve this metabolic disorder. Two weeks of treatment with dapagliflozin improved glucose utilization and was accompanied by reduced glucose production and enhanced glucose influx into liver tissue, but the treatment showed no effect on glucose uptake in skeletal muscle and adipose tissue ${ }^{[13]}$. Similar results have been described for other SGLT-2 inhibitors, for example, T-1095 and empagliflozin ${ }^{[14,15]}$. Gluco- or lipotoxicity contributes to the decline of $\beta$-cell function and mass ${ }^{[16]}$. The prevention of hyperglycemia by deleting SGLT2 in $d b / d b$ mice preserved pancreatic cell function in vivo ${ }^{[17]}$. Chronic phlorizin administration restored insulin secretion and normalized $\beta$-cell volume and gene expression ${ }^{[18-20]}$. Long-term studies of canagliflozin and dapagliflozin treatment yielded similar results $^{[21,22]}$. These data indicate that long-term treatment with SGLT2 inhibitors in animal models of T2DM can protect $\beta$-cell function.

SHR3824 is a novel SGLT2 inhibitor, which is structurally different from other SGLT2 inhibitors that are currently available or in the late stages of clinical development. In this study, we characterized the in vitro potency of SHR3824 to inhibit SGLT2 and its selectivity on SGLT1. In addition, we evaluated the effects of acute and chronic SHR3824 treatment on urinary glucose excretion and blood glucose levels in normal mice, GK rats and $d b / d b$ mice. Moreover, the effects of chronic administration of SHR3824 on the insulin sensitivity of skeletal muscle and pancreatic $\beta$-cell function in $d b / d b$ mice were investigated.

\section{Materials and methods}

\section{Chemicals}

SHR3824 ((1R,2S,3S,4R,5R)-5-(4-Chloro-3-(4-ethoxy-3-fluorobenzyl)phenyl)-1-(hydroxymethyl)-6,8-dioxabicyclo[3.2.1] octane-2,3,4-triol, Figure 1A) and dapagliflozin (BMS512148) were synthesized by the Jiangsu Hengrui Pharmaceutical Co, Ltd (Lianyungang, China).

A

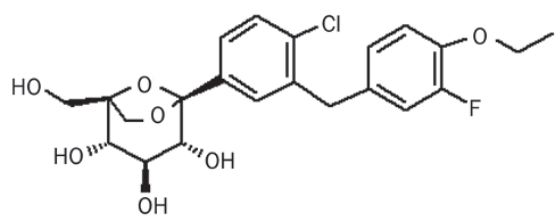

SHR3824

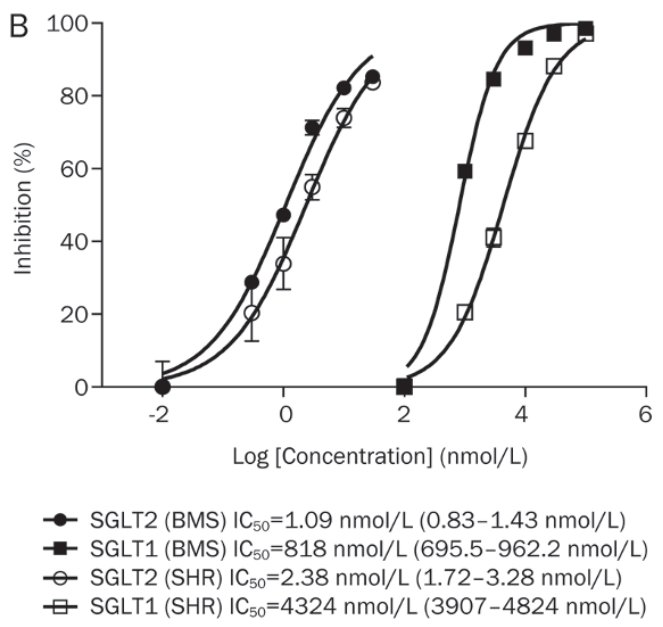

Figure 1. The chemical structure of SHR3824 (A) and in vitro inhibition of human SGLT2 and SGLT1 by SHR3824 and BMS512148 (B). Data are presented as the mean of two experiments. SGLT1 or SGLT2 expression plasmids were transfected into HEK293 cells. An AMG uptake experiment was performed using transiently transfected cells, and the 95\% confidence limits of the $\mathrm{IC}_{50}$ values for each SGLT were calculated.

\section{Animals}

Male ICR (Imprinting Control Region) mice, GK rats and Wistar rats were purchased from the Shanghai SLAC Laboratory Animal Co, Ltd (Shanghai, China). C57B6.Cg-m ${ }^{+/+}$Leprdb/J $(d b / d b)$ mice and their lean littermates ${ }^{+/+}$(The Jackson Laboratory, Bar Harbor, ME, USA) were bred at the Shanghai Institute of Materia Medica (SIMM), Chinese Academy of Sciences. The animals were maintained under a 12-h light-dark cycle with free access to water and food. All animal experiments were approved by the Animal Care and Use Committee, Shanghai Institute of Materia Medica, Chinese Academy of Sciences.

The Inhibitory Effects on Human SGLT1 and SGLT2 Human SGLT1 or SGLT2 cDNA (OriGene Technologies, Rockville, MD, USA) was ligated into the pCDNA3.1 vector. For 
the AMG (alpha-methyl- $D$-glucopyranoside) uptake experiment, HEK293 cells (ATCC) were seeded into a 24-well collagen-coated tissue culture plate at a density of $8 \times 10^{4}$ cells/well in Dulbecco's modified Eagle's medium (Sigma-Aldrich) containing $10 \%$ fetal bovine serum. After $24 \mathrm{~h}$, each plasmid was transfected into HEK293 cells using Lipofectamine 2000 (Invitrogen, Carlsbad, CA, USA), and the cells were used $2 \mathrm{~d}$ after transfection. The cells were washed twice with the pretreatment buffer ( $10 \mathrm{mmol} / \mathrm{L}$ HEPES, $5 \mathrm{mmol} / \mathrm{L}$ Tris, $140 \mathrm{mmol} / \mathrm{L}$ choline chloride, $2 \mathrm{mmol} / \mathrm{L} \mathrm{KCl}, 1 \mathrm{mmol} / \mathrm{L} \mathrm{CaCl} 2$, and 1 $\mathrm{mmol} / \mathrm{L} \mathrm{MgCl}_{2}, \mathrm{pH} 7.4$ ), then incubated with the uptake buffer (10 mmol/L HEPES, $5 \mathrm{mmol} / \mathrm{L}$ Tris, $140 \mathrm{mmol} / \mathrm{L} \mathrm{NaCl}, 2$ $\mathrm{mmol} / \mathrm{L} \mathrm{KCl}, 1 \mathrm{mmol} / \mathrm{L} \mathrm{CaCl}_{2}$, and $1 \mathrm{mmol} / \mathrm{L} \mathrm{MgCl}_{2}, \mathrm{pH}$ 7.4) containing different concentrations of SHR3824 or BMS512148 for $15 \mathrm{~min}$, followed by the addition of ${ }^{14} \mathrm{C}$-labeled $(4 \mu \mathrm{mol} / \mathrm{L})$ and non-labeled AMG $(10 \mu \mathrm{mol} / \mathrm{L})$ for $2 \mathrm{~h}$ at $37^{\circ} \mathrm{C}$. The cells were washed twice with ice-cold washing buffer (pretreatment buffer containing $100 \mu \mathrm{mol} / \mathrm{L}$ phlorizin) and then solubilized in $200 \mathrm{mmol} / \mathrm{L} \mathrm{NaOH}$. The radioactivity was measured using a liquid scintillation counter. The dose-response curves were fitted using GraphPad Prism (GraphPad Software) to determine the inhibitor concentration at the half-maximal response $\left(\mathrm{IC}_{50}\right)$.

\section{The effect of acute SHR3824 treatment on normal mice}

To examine the effect of acute SHR3824 treatment on blood glucose after an oral glucose challenge, $0.1,0.3,1.0$ or 3.0 $\mathrm{mg} / \mathrm{kg}$ SHR3824, $1.0 \mathrm{mg} / \mathrm{kg}$ BMS512148 or vehicle $(0.25 \%$ CMC-Na) was orally administered to $5 \mathrm{~h}$-fasted ICR mice $(n=$ 10 in each group) $60 \mathrm{~min}$ prior to an oral glucose load (2.5 $\mathrm{g} / \mathrm{kg}$ ). The blood glucose levels were measured $60 \mathrm{~min}$ before the glucose load, and 0, 15, 30, 60, and $120 \mathrm{~min}$ after the glucose load.

\section{The anti-diabetic effects of acute and chronic SHR3824} treatment on type 2 diabetic GK rats

Seven-week old male GK rats were fed a high-fat diet (M04-F; SLAC, Shanghai, China) for approximately 8 weeks before experimentation. At approximately 15 weeks of age, animals with similar blood glucose, $\mathrm{HbA1c}$ and body weight were randomly divided into vehicle or compound treatment groups ( $n=12$ in each group). Wistar rats fed a normal diet were used as the lean control. SHR3824 $(0.3,1.0$, or $3.0 \mathrm{mg} / \mathrm{kg})$, BMS512148 $(1.0 \mathrm{mg} / \mathrm{kg})$ or vehicle $(0.25 \%$ CMC-Na) was orally administered to GK rats once daily for $41 \mathrm{~d}$. To examine the effects of acute and chronic SHR3824 treatment on urine and blood glucose levels, the animals were placed into metabolic cages on $\mathrm{d} 1$ and 32 of treatment. The blood glucose levels were determined before dosing and 2, 4, 6, 9, and $24 \mathrm{~h}$ postdosing. Urine was collected at $6 \mathrm{~h}$ and $24 \mathrm{~h}$ post-dosing for glucose measurements. To assess the anti-diabetic effects of chronic SHR3824 treatment in GK rats, non-fasting ( $24 \mathrm{~h}$ postdosing) and fasting ( $6 \mathrm{~h}$ fasted and $6 \mathrm{~h}$ post-dosing) blood glucose, body weight and food consumption were measured at fixed time intervals. Blood samples were collected for $\mathrm{HbA1c}$ measurements on treatment $\mathrm{d} 38$.
The anti-diabetic effects of acute and chronic SHR3824 treatment on type 2 diabetic $d b / d b$ mice

Seven-week old $d b / d b$ mice were divided into 5 groups $(n=12$ in each group) based on non-fasting and fasting blood glucose, serum insulin levels and body weight. Wild-type littermates were used as the lean control. SHR3824 $(0.3,1.0$, or $3.0 \mathrm{mg} / \mathrm{kg})$, BMS512148 $(1.0 \mathrm{mg} / \mathrm{kg})$ or vehicle $(0.25 \%$ CMC$\mathrm{Na}$ ) were orally administered daily to $d b / d b$ mice for $43 \mathrm{~d}$. To examine the effects of acute and chronic SHR3824 treatment on urine and blood glucose levels, the animals were placed into metabolic cages on d 1, 13, and 40 of treatment. Urine was collected over a $6 \mathrm{~h}$ period after compound administration for glucose measurements. Blood glucose levels were determined before dosing and 2, 4, 6, 9, and $24 \mathrm{~h}$ post-dosing. To assess the anti-diabetic effect of chronic SHE3824 treatment in $d b / d b$ mice, non-fasting ( $24 \mathrm{~h}$ post-dosing) and fasting ( $6 \mathrm{~h}$ fasted and $6 \mathrm{~h}$ post-dosing) blood glucose, body weight and food consumption were measured at fixed time intervals. Blood samples were collected from mice fasted for $6 \mathrm{~h}$ for insulin measurements. At the end of treatment, the soleus muscles were isolated from SH3824 $(3.0 \mathrm{mg} / \mathrm{kg})$ treated and vehicletreated control mice for 2-deoxyglucose uptake measurements. The pancreases of SH3824 $(3.0 \mathrm{mg} / \mathrm{kg})$, BMS512148 $(1.0 \mathrm{mg} / \mathrm{kg})$ treated or vehicle-treated mice were isolated and fixed for immunohistochemical analyses of insulin.

\section{Measurements of 2-deoxyglucose uptake}

The soleus muscles were isolated and incubated in pregassed $\left(95 \% \mathrm{O}_{2} / 5 \% \mathrm{CO}_{2}\right) \mathrm{KHB}$ buffer $(\mathrm{NaCl} 118.5 \mathrm{mmol} / \mathrm{L}$, $\mathrm{KCl} 4.7 \mathrm{mmol} / \mathrm{L}, \mathrm{KH}_{2} \mathrm{PO}_{4} 1.2 \mathrm{mmol} / \mathrm{L}, \mathrm{NaHCO}_{3} 25 \mathrm{mmol} / \mathrm{L}$, $\mathrm{CaCl}_{2} \cdot 2 \mathrm{H}_{2} \mathrm{O} 2.5 \mathrm{mmol} / \mathrm{L}, \mathrm{MgCl}_{2} \cdot 7 \mathrm{H}_{2} \mathrm{O} 1.2 \mathrm{mmol} / \mathrm{L}$, and HEPES $5 \mathrm{mmol} / \mathrm{L}$ ) containing $5 \mathrm{mmol} / \mathrm{L}$ glucose and 15 $\mathrm{mmol} / \mathrm{L}$ mannitol with or without $120 \mathrm{nmol} / \mathrm{L}$ insulin for 30 min. Thereafter, muscles were rinsed in glucose-free KHB buffer with or without insulin for $10 \mathrm{~min}$, then transferred to vials containing $1 \mathrm{mmol} / \mathrm{L}$ 2-deoxy-D-[1,2- $\left.{ }^{3} \mathrm{H}\right]$ glucose $\left(9.25 \times 10^{4}\right.$ $\mathrm{Bq} / \mathrm{mL})$ and $19 \mathrm{mmol} / \mathrm{L}\left[{ }^{14} \mathrm{C}\right]$ mannitol $\left(2.59 \times 10^{4} \mathrm{~Bq} / \mathrm{mL}\right)$ (Perkin Elmer, MA, USA) with or without $120 \mathrm{nmol} / \mathrm{L}$ insulin and incubated for $20 \mathrm{~min}$. The gas phase $\left(95 \% \mathrm{O}_{2} / 5 \% \mathrm{CO}_{2}\right)$ and temperature $\left(30^{\circ} \mathrm{C}\right)$ were maintained during the muscle incubation. The muscles were frozen in liquid nitrogen and processed as described previously ${ }^{[23]}$. The glucose transport activity is expressed as $\mu \mathrm{mol}$ glucose analogue accumulated per $\mathrm{mL}$ of intracellular water per hour.

\section{Immunohistochemical analysis}

The pancreatic samples were fixed in $10 \%$ buffered formalin for $1 \mathrm{~d}$ and subsequently embedded in paraffin. The paraffin sections $(3 \mu \mathrm{m})$ were cut, deparaffinized, rehydrated and placed in 3\% hydrogen peroxide for $10 \mathrm{~min}$ at room temperature. The sections were then heated twice for $15 \mathrm{~min}$ at $90^{\circ} \mathrm{C}$ in a microwave, rinsed with Tris-buffered saline with Tween 80 (TBS-T) twice for $5 \mathrm{~min}$ and then blocked with 5\% normal goat serum (Beijing Dingguo Reagent Co, Ltd, Beijing, China) for $45 \mathrm{~min}$. The sections were then incubated with the primary antibody, ready-to-use guinea pig polyclonal anti- 
insulin antibody (Cat\#: 58916, Abcam), overnight at $4{ }^{\circ} \mathrm{C}$. The sections were washed with TBS-T and blocked with $10 \%$ normal goat serum for $30 \mathrm{~min}$. Bound antibody was detected using a ready-to-use rabbit polyclonal secondary antibody to guinea pig IgG H\&L (Cat\#: ab6771, Abcam) for $30 \mathrm{~min}$. The sections were rinsed with TBS-T and developed for $15 \mathrm{~min}$ using a DAB substrate kit (Sangon Biotech, Shanghai, China). Finally, the slides were washed with TBS-T, counterstained with hematoxylin, dehydrated and mounted.

\section{Sample handling and analysis}

Blood glucose levels were measured using an Accu-Chek Advantage Glucose Monitor (Roche, Diagnostics GmbH, Germany). The urinary glucose levels were determined by a glucose oxidase method (Applygen, Beijing, China). The serum insulin levels were measured using a 96-well ultra sensitive mouse insulin ELISA kit (Crystal Chem Inc, Downers Grove, IL, USA). The HbA1c was measured using an automatic biochemical analyzer (7020, Hitachi Instrument Co, Ltd, Japan).

\section{Statistical analysis}

All data are expressed as the mean \pm SEM. The statistical analysis between two groups was performed using an unpaired Student's $t$-test. A value of $P<0.05$ was considered to be statistically significant.

\section{Results}

The inhibitory effects of SHR3824 on human SGLT2 and SGLT1 The inhibitory effects of SHR3824 and BMS512148 on AMG uptake in HEK293 cells transiently transfected with a human SGLT expression plasmid are shown as $\mathrm{IC}_{50}$ values in Figure 1B. SHR3824 exhibits an $\mathrm{IC}_{50}$ of $2.38 \mathrm{nmol} / \mathrm{L}$ against hSGLT2 that is similar to the $\mathrm{IC}_{50}$ of $1.09 \mathrm{nmol} / \mathrm{L}$ observed for BMS512148. The $\mathrm{IC}_{50}$ values of SHR3824 and BMS512148 against hSGLT1 are 4324 and $818 \mathrm{nmol} / \mathrm{L}$, respectively. The ratios of selectivity ( $\mathrm{IC}_{50}$ of hSGLT1/hSGLT2) of SHR3824 and BMS512148 were 1817 and 750, respectively. These data suggest that SHR3824 is a potent and selective SGLT2 inhibitor.

\section{The effect of acute administration of SHR3824 on blood glucose} levels in normal mice

Figure 2A depicts the glucose profiles obtained during the oral glucose tolerance test (OGTT) in ICR mice after oral administration of SHR3824 $(0.1-3.0 \mathrm{mg} / \mathrm{kg})$, BMS512148 $(1.0 \mathrm{mg} / \mathrm{kg})$ or vehicle. SHR3824 administration produced a dose-related improvement of glucose tolerance and caused a significant decrease in the glucose $\mathrm{AUC}_{0-120 \mathrm{~min}}$ of $20.6 \%, 26.8 \%$, and $31.6 \%$ at doses of $0.3,1.0$, and $3.0 \mathrm{mg} / \mathrm{kg}(P<0.05)$, while administration of $1.0 \mathrm{mg} / \mathrm{kg}$ BMS512148 showed a similar glucose lowering effect with a reduction rate of $31.8 \%$ (Figure 2B). Therefore, a single oral dose of SHR3824 improved glucose tolerance in normal mice after a glucose challenge.

The effect of SHR3824 on urinary glucose excretion and blood glucose after acute and multiple dosing in GK rats

To assess whether acute administration and multiple doses
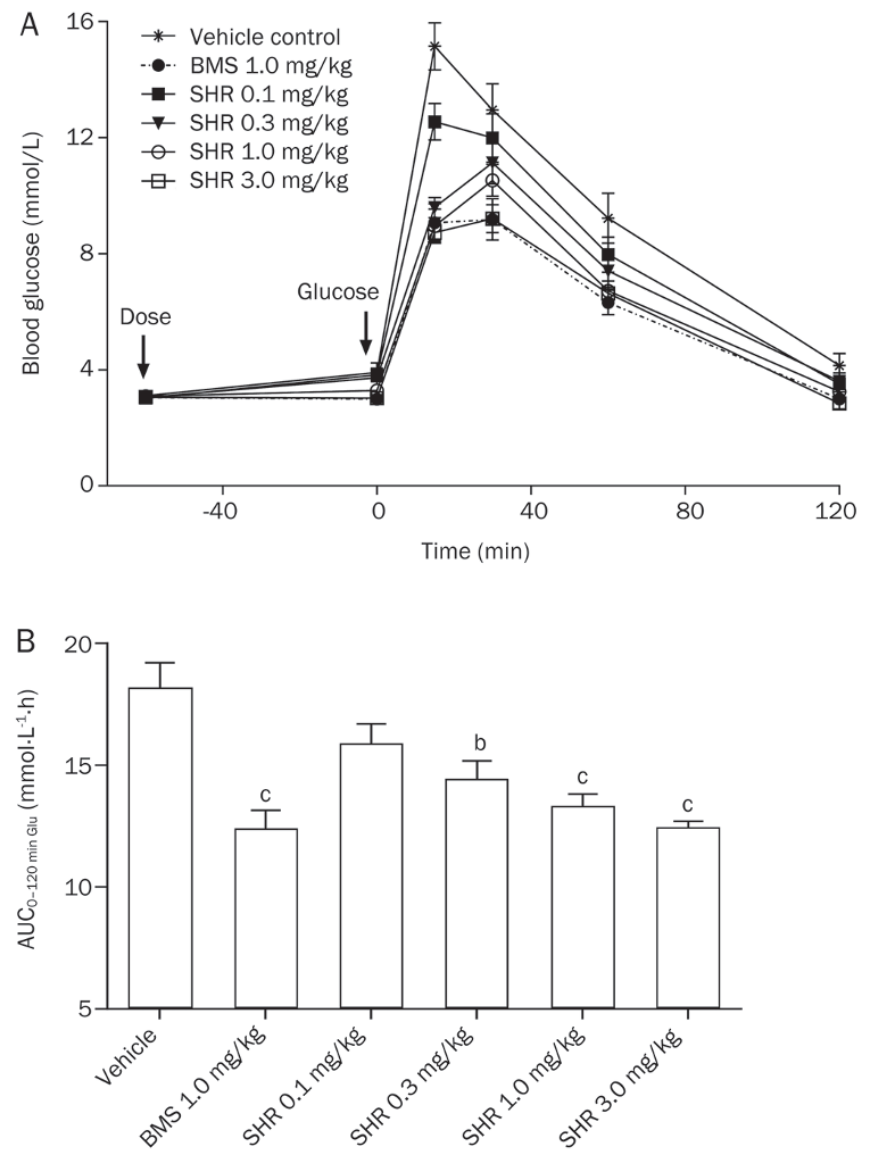

Figure 2. The effects of acute administration of SHR3824 on glucose levels in normal mice. SHR3824, BMS512148, or vehicle was orally administered to overnight-fasted normal ICR mice 60 min prior to an oral glucose load $(2.5 \mathrm{~g} / \mathrm{kg})$. The data represent the mean \pm SEM. $n=10$. ${ }^{\mathrm{b}} P<0.05,{ }^{\mathrm{c}} P<0.01$ vs control.

of SHR3824 increased urinary glucose excretion by inhibiting renal glucose reabsorption, we orally administered SHR3824 $(0.3,1.0$, or $3.0 \mathrm{mg} / \mathrm{kg})$ to GK rats once daily for $41 \mathrm{~d}$. The blood glucose, urine volume and urinary glucose excretion were measured on $\mathrm{d} 1$ and 32 of treatment. As shown in Figure 3 , the urine volume and urinary glucose excretion were increased by either acute or multiple oral administration of SHR3824 in a dose-dependent manner, and most of the glucose was excreted within $6 \mathrm{~h}$ of administration. On $\mathrm{d} 1$ of treatment, $0.3,1.0$, or $3.0 \mathrm{mg} / \mathrm{kg}$ of SHR3824 increased the urinary glucose excretion during the first 6 h by 1.8-, 2.1-, and 2.2-fold compared with the vehicle-treated controls $(P<0.01)$ while BMS512148 $(1.0 \mathrm{mg} / \mathrm{kg})$ increased the urinary glucose excretion by 3.0 -fold $(P<0.01)$. On d 32 of treatment, $0.3,1.0$, or $3.0 \mathrm{mg} / \mathrm{kg}$ of SHR3824 increased the urinary glucose excretion during the first $6 \mathrm{~h}$ by 1.6-, 1.8-, and 1.8-fold compared with the vehicle-treated controls $(P<0.01)$ while BMS512148 $(1.0$ $\mathrm{mg} / \mathrm{kg}$ ) increased the urinary glucose excretion by 2.1 -fold $(P<0.01)$. Thus, SHR3824 was confirmed as a selective SGLT2 inhibitor capable of increasing urinary glucose excretion in a 
A

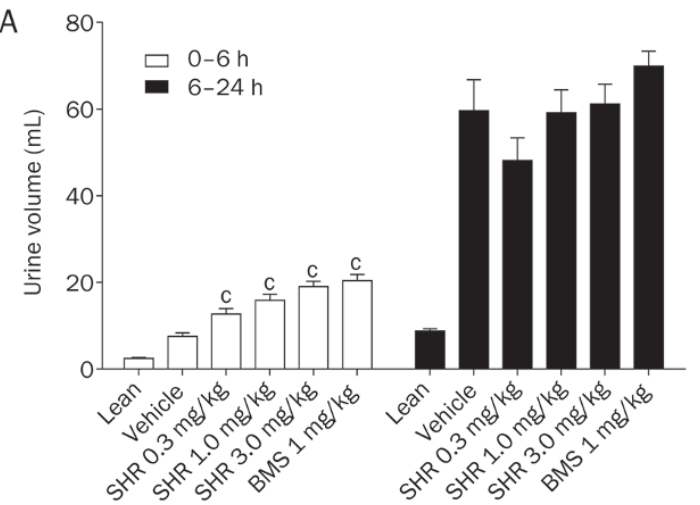

C

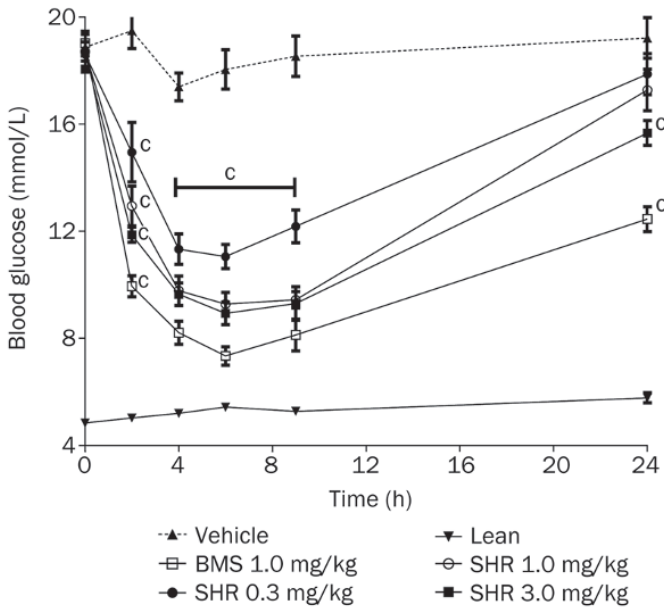

E

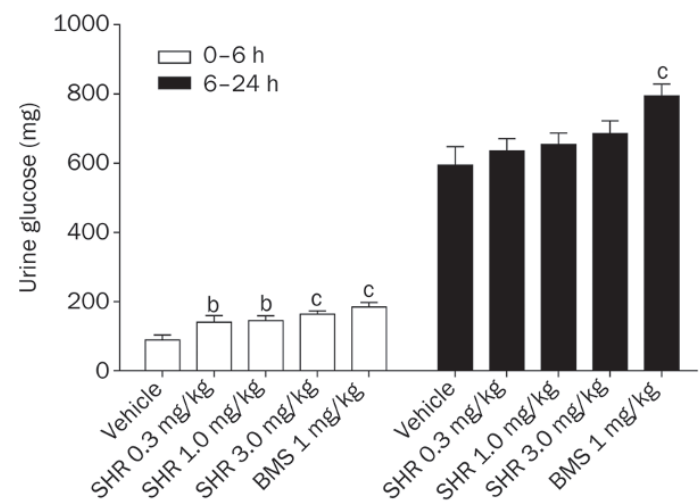

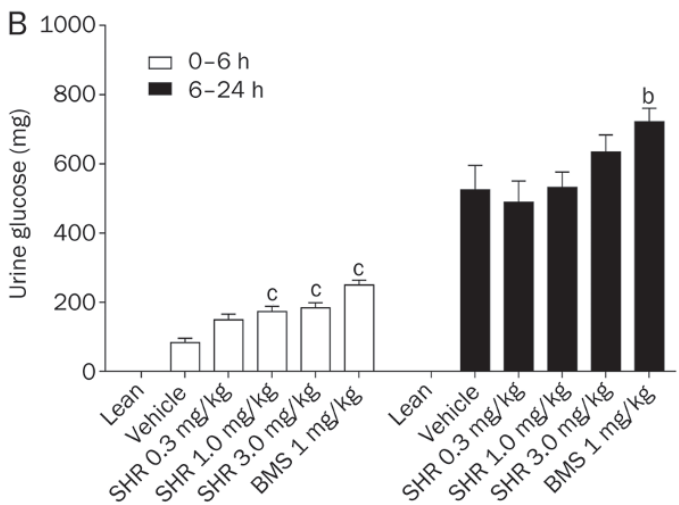

D

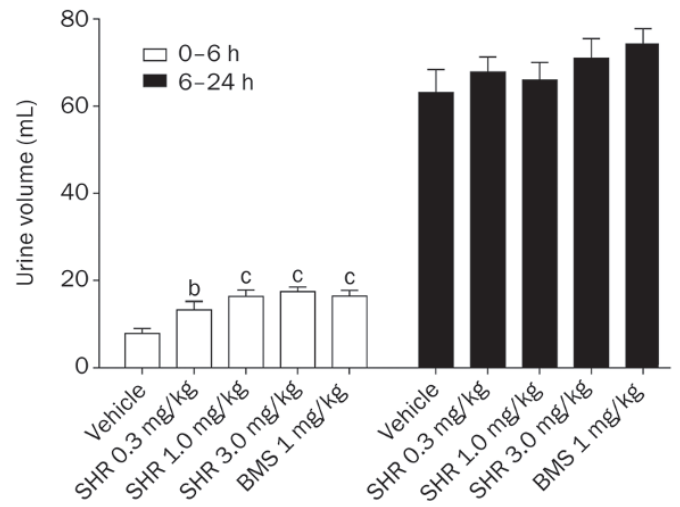

F
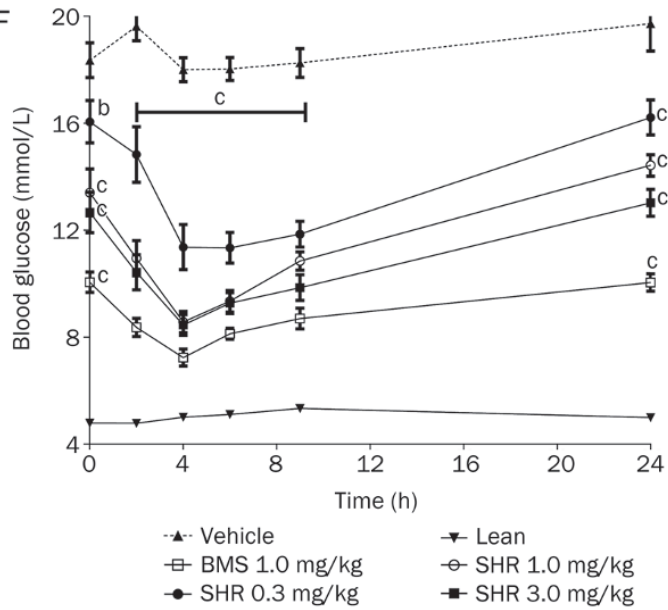

Figure 3. The effect of SHR3824 on urinary glucose excretion and blood glucose levels after acute and multiple dosing in GK rats. SHR3824, BMS512148, or vehicle was orally administered to GK rats once daily for $41 \mathrm{~d}$. Urine volume, urinary glucose excretion and blood glucose levels were determined on treatment d 1 [(A) Urine volume; (B) urinary glucose excretion; and (C) blood glucose levels] and d 32 [(D) Urine volume; (E) urinary glucose excretion; and $(\mathrm{F})$ blood glucose levels]. ${ }^{\mathrm{b}} \mathrm{P}<0.05,{ }^{\mathrm{C}} \mathrm{P}<0.01 \mathrm{vs}$ control. The data represent the mean \pm SEM. $n=12$.

dose dependent manner. As shown in Figure 3C and 3F, GK rats exhibited hyperglycemia. The administration of SHR3824 or BMS512148 to GK rats produced a significant decrease in blood glucose levels. On d 1 of treatment, $0.3,1.0$, or $3.0 \mathrm{mg} /$ $\mathrm{kg}$ of SHR3824 reduced the glucose $\mathrm{AUC}_{0-24 \mathrm{~h}}$ values by $23.7 \%$, $32.7 \%$, and $36.5 \%$, while $1.0 \mathrm{mg} / \mathrm{kg}$ of BMS512148 reduced the glucose $\mathrm{AUC}_{0-24 \mathrm{~h}}$ levels by $46.5 \%$. On d 32 of treatment, 0.3 , 1.0 , or $3.0 \mathrm{mg} / \mathrm{kg}$ of SHR3824 reduced the glucose $\mathrm{AUC}_{0-24}$ h values by $27.9 \%, 37.5 \%$, and $42.4 \%$, while $1.0 \mathrm{mg} / \mathrm{kg}$ of BMS512148 reduced the glucose $\mathrm{AUC}_{0-24 \mathrm{~h}}$ values by $52.3 \%$. The in vivo glucose lowering potency of SHR3824 on d 1 and 32 were comparable, suggesting that the multiple administra- 

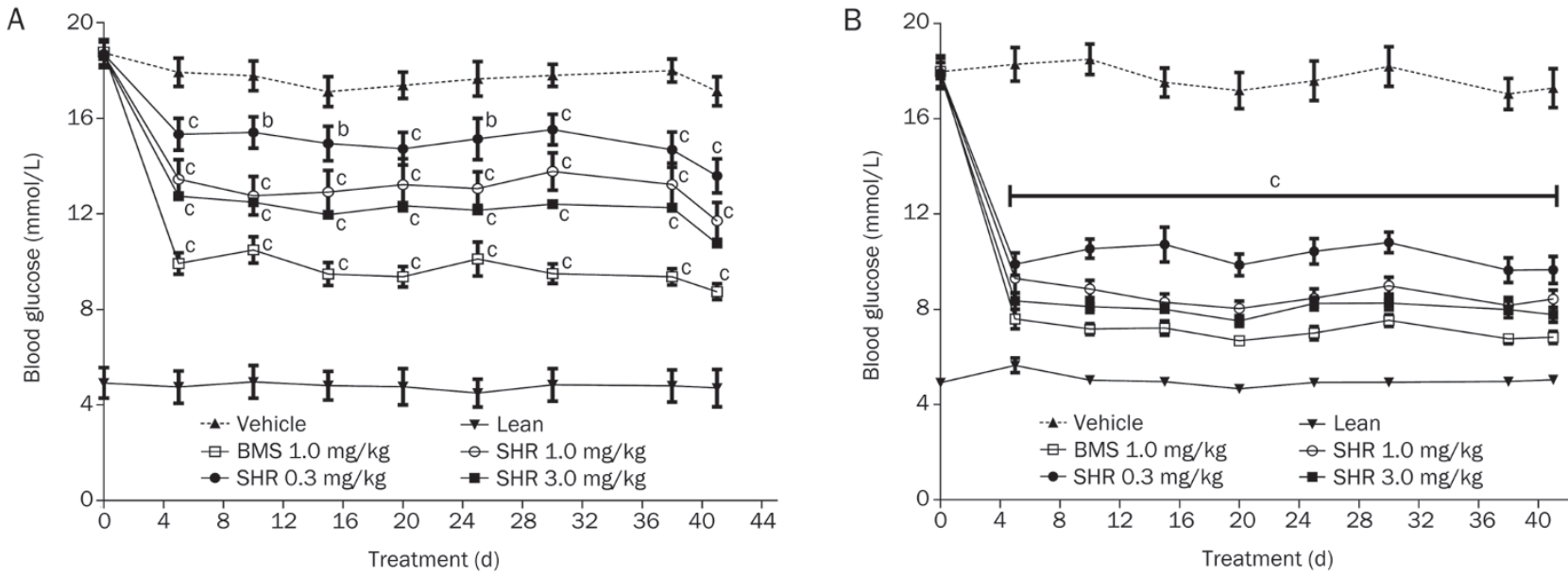

C
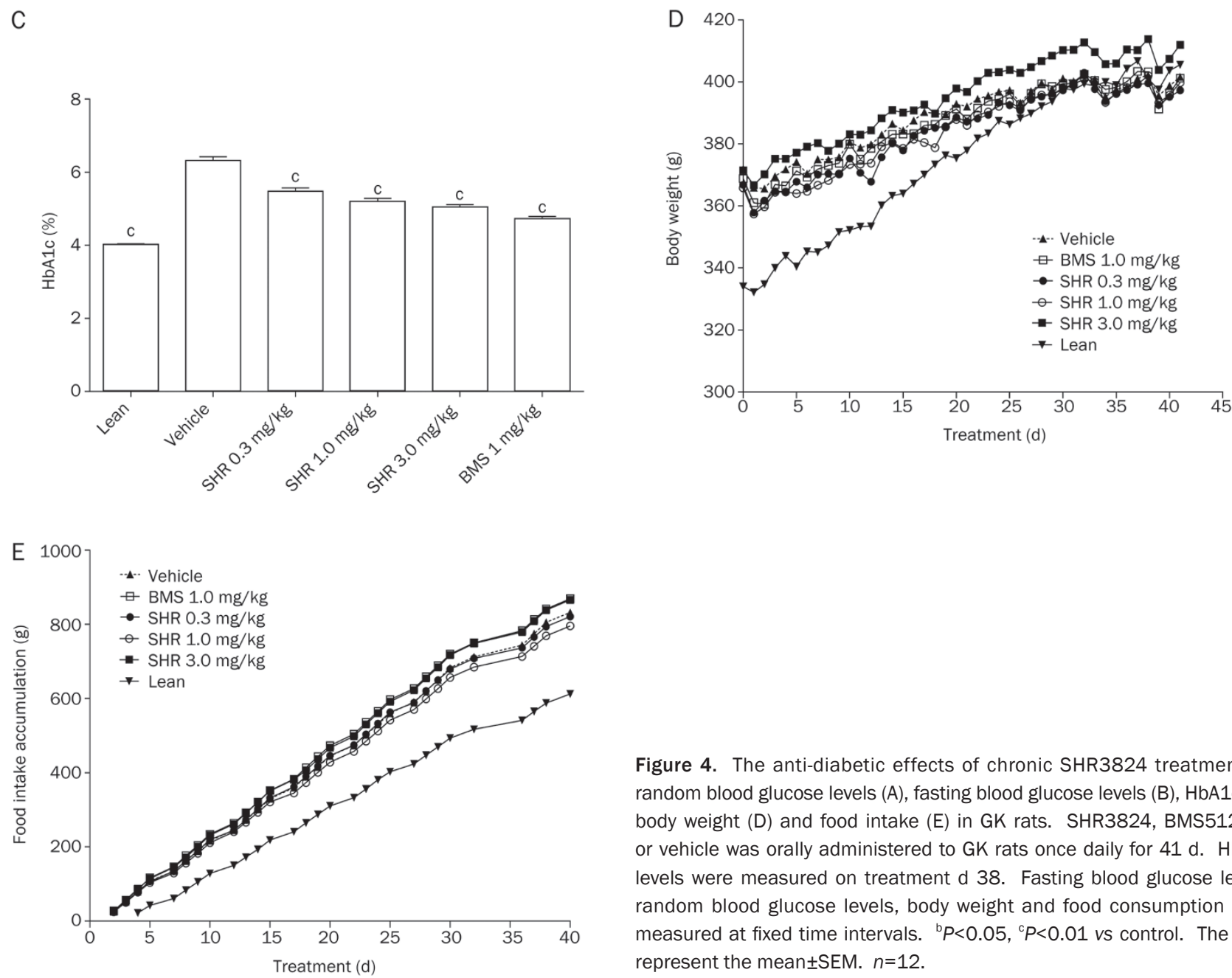

Figure 4. The anti-diabetic effects of chronic SHR3824 treatment on random blood glucose levels $(A)$, fasting blood glucose levels $(B), H b A 1 c(C)$, body weight (D) and food intake (E) in GK rats. SHR3824, BMS512148 or vehicle was orally administered to GK rats once daily for $41 \mathrm{~d}$. HbA1c levels were measured on treatment $d$ 38. Fasting blood glucose levels, random blood glucose levels, body weight and food consumption were measured at fixed time intervals. ${ }^{b} P<0.05,{ }^{c} P<0.01$ vs control. The data represent the mean \pm SEM. $n=12$.

tion of SHR3824 did not exhibit tachyphylaxis with respect to its antidiabetic activity.

The anti-diabetic effects of chronic SHR3824 treatment on GK rats

SHR3824 $(0.3,1.0$, or $3.0 \mathrm{mg} / \mathrm{kg})$, BMS512148 $(1.0 \mathrm{mg} / \mathrm{kg})$ or

vehicle was orally administered to GK rats once daily for $41 \mathrm{~d}$. As shown in Figure $4 \mathrm{~A}$ and $4 \mathrm{~B}$, the fasting and non-fasting glucose levels of GK rats were significantly higher than that of lean controls throughout treatment. The administration of SHR3824 caused significant reductions in the non-fasting and fasting blood glucose levels after $5 \mathrm{~d}$ of treatment compared 

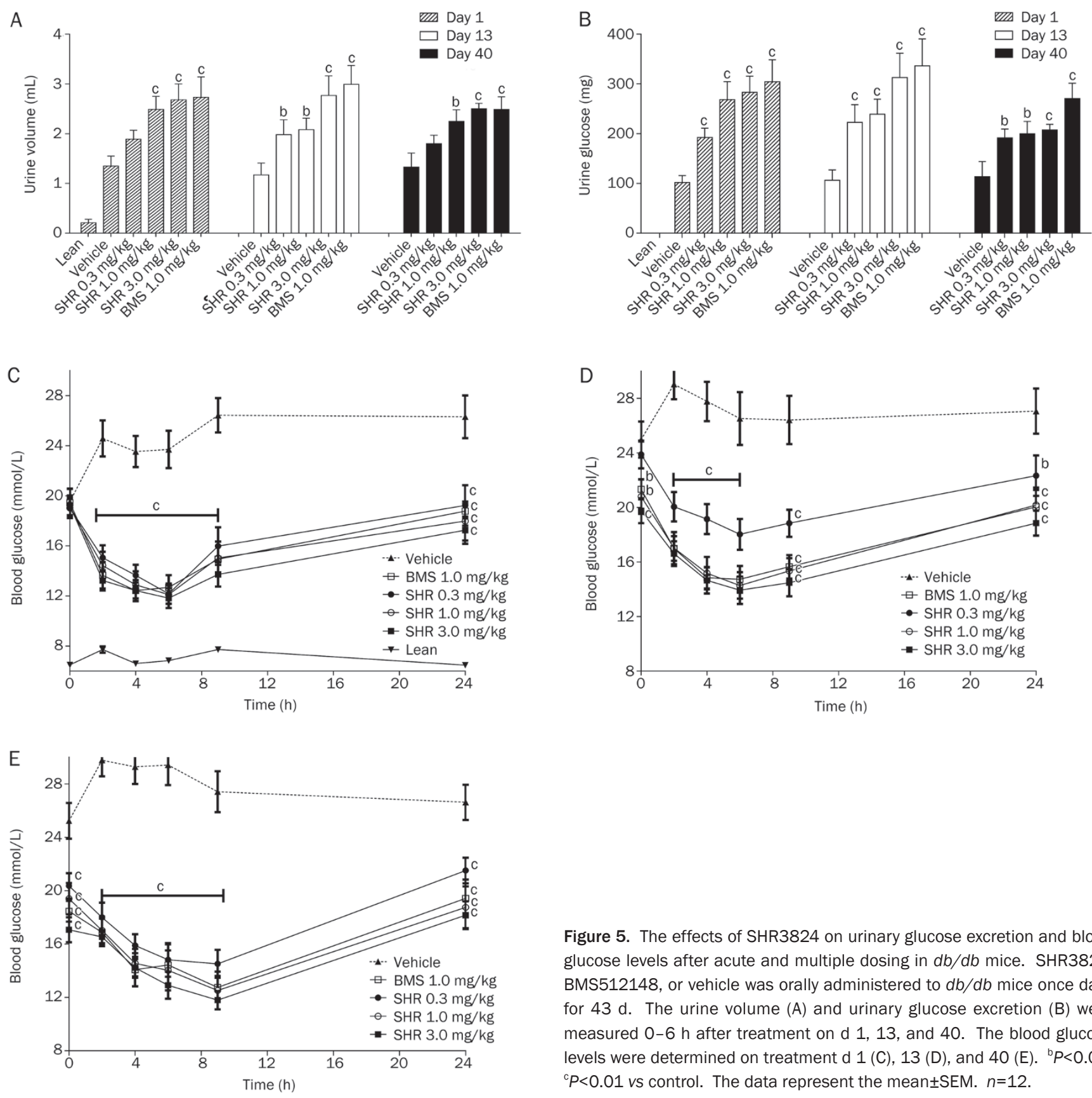

with the vehicle-treated controls $(P<0.01)$. This antihyperglycemic effect was sustained throughout treatment. After 38 $\mathrm{d}$ of treatment, GK rats treated with $0.3,1.0$, or $3.0 \mathrm{mg} / \mathrm{kg}$ of SHR3824 had HbA1c values of $5.47 \% \pm 0.10 \%, 5.19 \% \pm 0.09 \%$, and $5.04 \% \pm 0.07 \%$, respectively, demonstrating a dosedependent decrease compared with vehicle-treated controls $(6.31 \% \pm 0.11 \%)(P<0.01)$. SHR3824 affected neither the body weight nor the food intake during the treatment period (Figure $4 \mathrm{D})$.

The effects of SHR3824 on urinary glucose excretion and blood glucose levels after acute and multiple dosing in $d b / d b$ mice

To evaluate the effects of acute and multiple dosing of

Figure 5. The effects of SHR3824 on urinary glucose excretion and blood glucose levels after acute and multiple dosing in $d b / d b$ mice. SHR3824, BMS512148, or vehicle was orally administered to $d b / d b$ mice once daily for $43 \mathrm{~d}$. The urine volume (A) and urinary glucose excretion (B) were measured 0-6 $\mathrm{h}$ after treatment on $\mathrm{d} 1,13$, and 40 . The blood glucose levels were determined on treatment $d 1(C), 13(D)$, and $40(E) .{ }^{b} P<0.05$, ${ }^{c} P<0.01$ vs control. The data represent the mean \pm SEM. $n=12$.

SHR3824 on urinary glucose excretion and blood glucose levels, 7-week old $d b / d b$ mice were orally treated with SHR3824 $(0.3,1.0$, or $3.0 \mathrm{mg} / \mathrm{kg})$, BMS512148 $(1.0 \mathrm{mg} / \mathrm{kg})$ or vehicle alone once daily for $43 \mathrm{~d}$. The blood glucose levels, urine volume and urinary glucose excretion were measured at $\mathrm{d} 1,13$, and 40 of treatment. As shown in Figure 5, SHR3824 caused a dose-dependent increase in urine volume and urinary glucose excretion between 0 and $6 \mathrm{~h}$ post-dose administration on treatment $\mathrm{d} 1,13$, and 40 , concomitant with a decrease in plasma glucose levels. On the first day of treatment, the acute administration of $0.3,1.0$, or $3.0 \mathrm{mg} / \mathrm{kg}$ SHR3824 caused a 1.9-, 2.6-, and 2.8-fold increase in urinary glucose excretion compared with vehicle treatment over a $6 \mathrm{~h}$ period post-dose 
administration that was accompanied by a $35.3 \%, 38.7 \%$, and $42.1 \%$ decrease in the glucose $\mathrm{AUC}_{0-24 \mathrm{~h}}$ values. On $\mathrm{d} 13$ and 40 of treatment, $0.3,1.0$, or $3.0 \mathrm{mg} / \mathrm{kg}$ SHR3824 showed similar effects, with a 2.1-, 2.2-, or 2.9-fold increase (d 13) and a 1.7-, $1.8-$, or 1.8 -fold increase (d 40) in urinary glucose excretion compared with vehicle-treated controls over a $6 \mathrm{~h}$ period postdose administration that was accompanied by a decrease in the glucose $\mathrm{AUC}_{0-24 \mathrm{~h}}$ values of $25.0 \%, 36.4 \%$, or $39.8 \%$ (d 13) and $37.1 \%, 44.1 \%$, or $46.7 \%$ (d 40$)$.
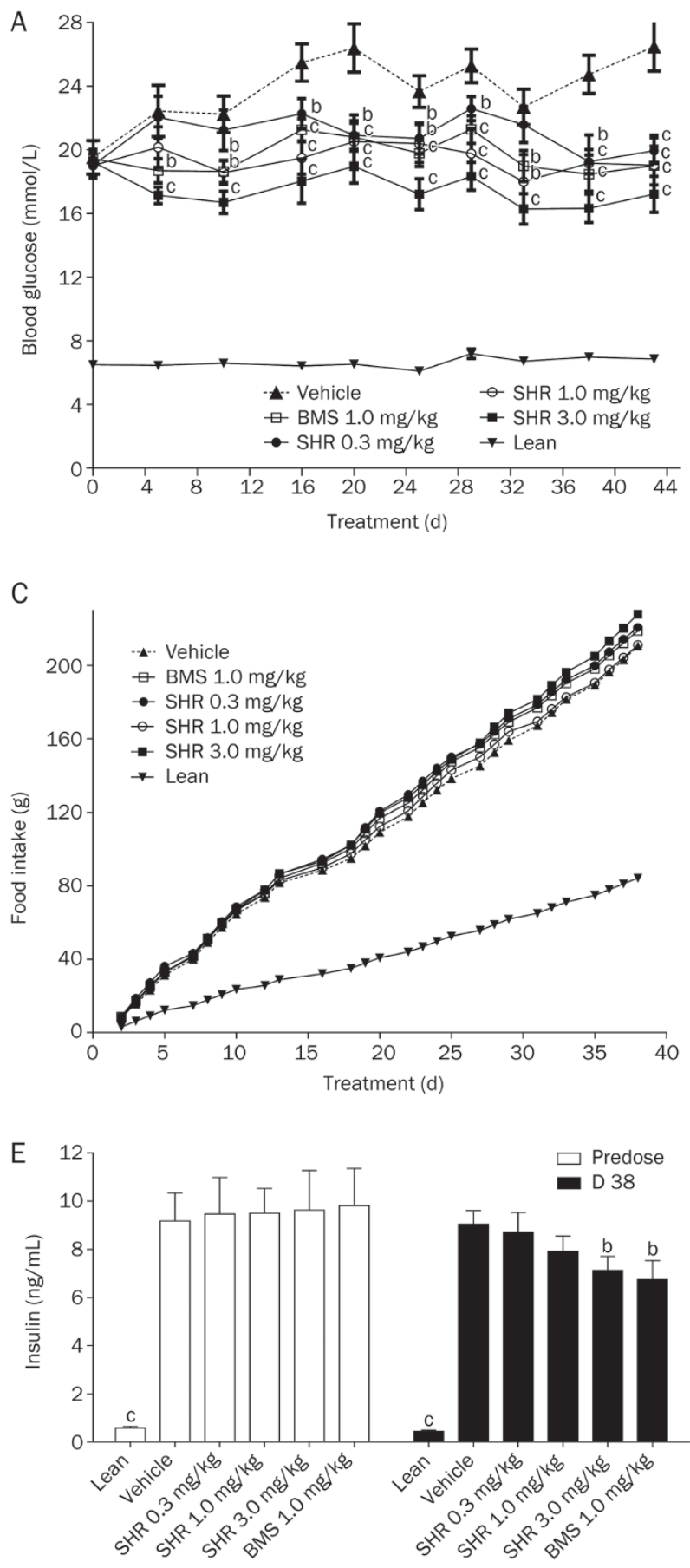

The anti-diabetic effects of chronic SHR3824 treatment on $d b / d b$ mice

The $d b / d b$ mice were treated orally with SHR3824 $(0.3,1.0$, or $3.0 \mathrm{mg} / \mathrm{kg})$, BMS512148 $(1.0 \mathrm{mg} / \mathrm{kg})$ or vehicle alone once daily for $43 \mathrm{~d}$. As shown in Figure 6, the administration of all three doses of SHR3824 caused significant reductions in the fasting blood glucose levels after $5 \mathrm{~d}$ of treatment compared with vehicle-treated controls $(P<0.01)$, and this effect was sustained throughout treatment. After $43 \mathrm{~d}$ of treatment with 0.3, 1.0 , or $3.0 \mathrm{mg} / \mathrm{kg}$ SHR3824, the non-fasting and fasting blood
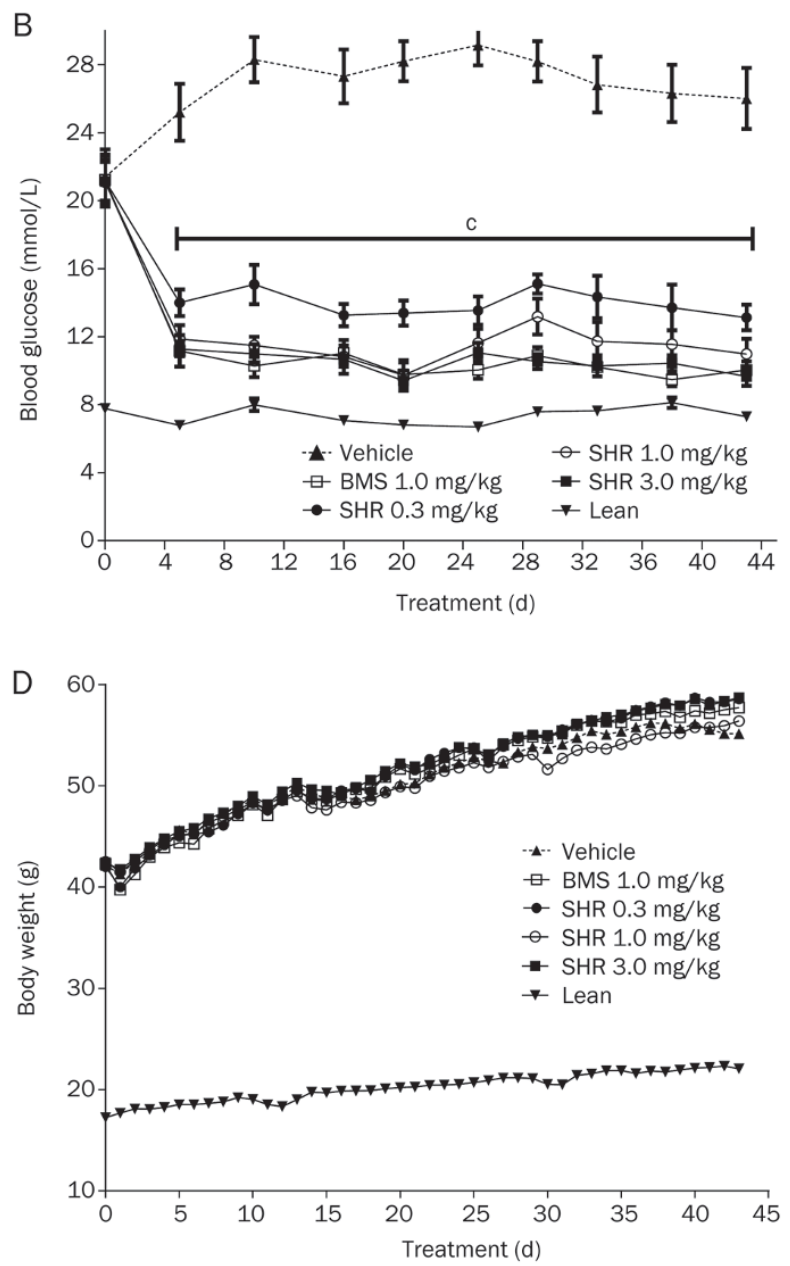

Figure 6. The anti-diabetic effects of chronic SHR3824 treatment on random blood glucose levels (A), fasting blood glucose levels (B), body weight (C), food intake (D) and insulin levels (E) in $d b / d b$ mice. SHR3824, BMS512148 or vehicle was orally administered to $d b / d b$ mice once daily for $43 \mathrm{~d}$. The fasting serum insulin levels were measured on treatment d 38. Fasting blood glucose levels, random blood glucose levels, body weight and food consumption were measured at fixed time intervals. ${ }^{\mathrm{b}} P<0.05,{ }^{\mathrm{c}} P<0.01$ vs control. The data represent the mean \pm SEM. $n=12$. 
glucose levels were significantly reduced by $24.7 \%, 28.2 \%$, or $35.1 \%$ and $49.5 \%, 57.8 \%$, or $62.9 \%$, respectively. SHR3824 affected neither the body weight nor the food intake during the treatment period.

To determine whether SHR3824 improved hyperinsulinemia in type 2 diabetic mice, serum fasting insulin levels were measured pre-dose and on treatment $d$ 38. As shown in Figure 6E, hyperinsulinemia was observed at the beginning of the experiment in all $d b / d b$ mice compared with lean mice. Treatment with $3.0 \mathrm{mg} / \mathrm{kg}$ of SHR3824 significantly reduced the serum insulin levels by $21.1 \%(P<0.05)$, while treatment with $1.0 \mathrm{mg} / \mathrm{kg}$ BMS512148 resulted in a comparable decrease of $25.3 \%$. These data suggest that chronic treatment with SHR3824 may improve the peripheral insulin sensitivity of $d b / d b$ mice. To further study the insulin sensitivity of skeletal muscle, the soleus muscles were isolated from SHR3824 (3.0 $\mathrm{mg} / \mathrm{kg}$ ) treated and vehicle-treated control mice at the end of treatment for measuring 2-deoxyglucose uptake (Figure 7). Insulin incubation stimulated 2-deoxyglucose uptake in the soleus muscles. Chronic treatment with SHR3824 significantly enhanced the insulin-stimulated glucose uptake in the soleus muscles of $d b / d b$ mice compared with vehicle-treated controls $(P<0.05)$. The insulin-stimulated glucose uptake was increased by $43 \%$ in the soleus muscles of vehicle-treated control mice, whereas an $84 \%$ increase in the insulin-stimulated glucose uptake was observed in the soleus muscles of SHR3824 treated mice.

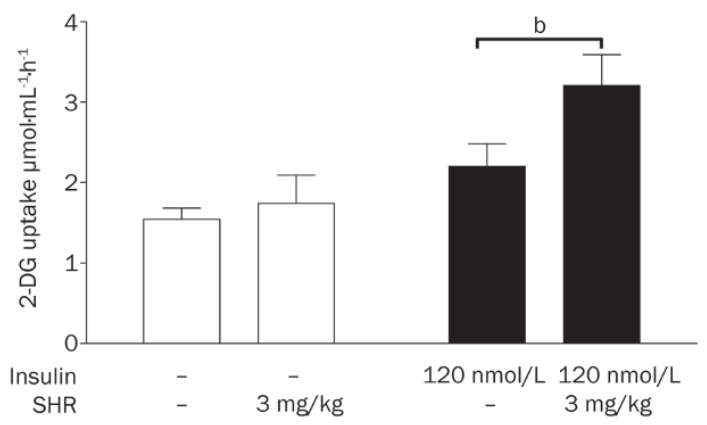

Figure 7. The effects of chronic SHR3824 treatment on glucose uptake in the soleus muscles of $d b / d b$ mice. Mice were treated with SHR3824 $(3.0 \mathrm{mg} / \mathrm{kg}$ ) or vehicle for $43 \mathrm{~d}$. The soleus muscles were isolated and 2-deoxyglucose uptake was measured at the end of the treatment. ${ }^{\mathrm{b}} P<0.05,{ }^{\mathrm{c}} P<0.01$ vs control. The data represent the mean \pm SEM. $n=12$.

To evaluate the chronic effects of SHR3824 treatment on pancreatic $\beta$-cell function, the pancreases of SHR3824 (3.0 $\mathrm{mg} / \mathrm{kg})$, BMS512148 (1.0 mg/kg), vehicle-treated control and lean control mice were isolated at the end of treatment and immunohistochemical analyses of insulin staining were performed. As shown in Figure 8, weak insulin staining with an irregular $\beta$-cell distribution was observed in the vehicletreated $d b / d b$ mice compared with vehicle-treated lean mice, indicating that $\beta$-cell function was impaired in the $d b / d b$ mice. SHR3824 treatment for $43 \mathrm{~d}$ significantly increased insulin
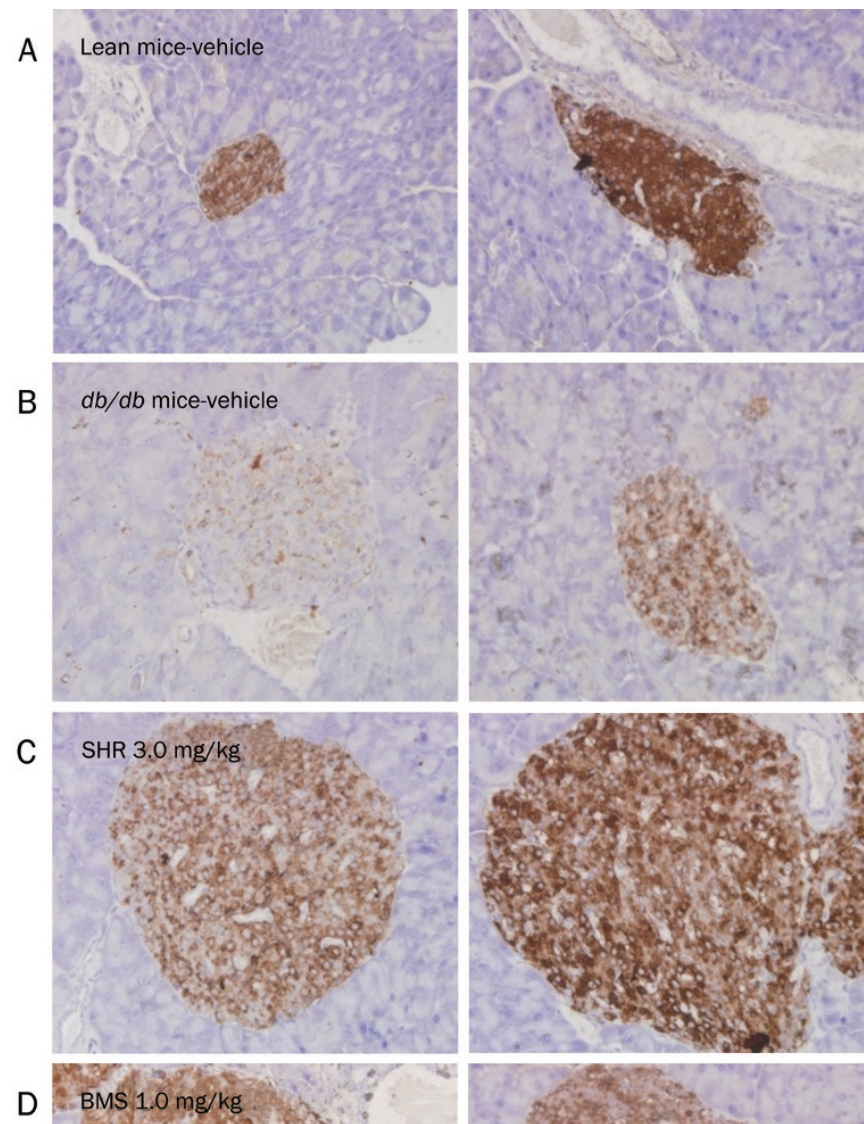

D
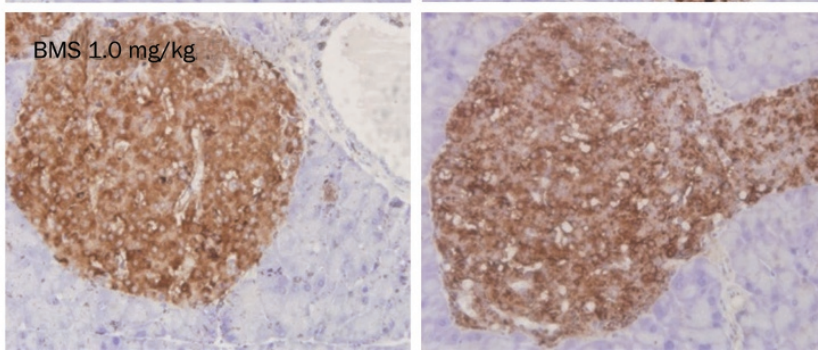

Figure 8. The effects of chronic SHR3824 treatment on pancreatic insulin staining in $d b / d b$ mice. The mice were treated with SHR3824 (3.0 $\mathrm{mg} / \mathrm{kg}$ ), BMS512148 (1.0 mg/kg), or vehicle for $43 \mathrm{~d}$. Pancreases were isolated and pancreatic sections were stained with anti-insulin antibodies after $6 \mathrm{~h}$ of fasting. (A) Vehicle-treated lean mice. (B) Vehicle-treated $d b / d b$ mice. (C) $d b / d b$ mice treated with $3.0 \mathrm{mg} / \mathrm{kg}$ SHR3824. (D) $d b / d b$ mice treated with $1.0 \mathrm{mg} / \mathrm{kg}$ BMS512148. The image magnification was $\times 40$.

staining and enhanced insulin antigen positivity with regular distribution of $\beta$-cells, indicating that $\beta$-cell function was improved. The chronic BMS512148 treatment showed similar effects.

\section{Discussion}

The correction of hyperglycemia by enhancing urinary glucose excretion is an approach that has been reported in the literature for many years. SGLT2 is responsible for most of the glucose reabsorption in the kidneys, and thus, it is a new molecular target for the treatment of diabetes. Several SGLT2 inhibitors are currently being developed for diabetes treat- 
ment ${ }^{[24]}$. One such compound, BMS512148, induces renal glucose excretion, thereby eliciting sustained glucose reduction in normal and type 2 diabetic subjects, in addition to animal models. This unique mechanism of utilizing SGLT2 inhibition for the treatment of hyperglycemia does not rely on insulin secretion or insulin action and thus has a low risk of inducing hypoglycemia. In addition, it has the potential to be weight-neutral or to promote weight loss, due to the elevated urinary glucose excretion ${ }^{[25]}$. This is an attractive therapeutic approach for diabetes that could be effective in a wide variety of patients. In the present study, we identified SHR3824 as a novel potent and selective SGLT2 inhibitor and evaluated the pharmacological effects of acute and chronic SHR3824 treatment on metabolic control in normal and diabetic rodent models.

The potency and selectivity of SHR3824 on SGLT2 inhibition was tested in HEK293 cells transiently transfected with human SGLT1 and SGLT2, using BMS512148 as a positive control. SHR3824 exhibited a strong inhibition of hSGLT2, with an $\mathrm{IC}_{50}$ value in the low nanomolar range but demonstrated a much weaker inhibition activity on $\mathrm{hSGLT1}$, with an $\mathrm{IC}_{50}$ value in the micromolar range. The potency and selectivity of SHR3824 is quite similar to that of the positive control compound, BMS512148. These data indicate that SHR3824 is a potent and selective SGLT2 inhibitor, and ensure that the majority of the pharmacology observed is due to renal SGLT2 inhibition.

An oral glucose tolerance test was performed in normal mice to investigate the effects of SHR3824 on postprandial blood glucose levels. The acute administration of SHR3824 exhibited good oral bioavailability and dose-dependently reduced the elevated blood glucose levels caused by oral glucose challenge. The minimal effective dose of SHR3824 required to reduce blood glucose levels was $0.3 \mathrm{mg} / \mathrm{kg}$, which caused $20.6 \%$ reduction of the glucose $\mathrm{AUC}_{0-120 \text { min }}$ values. These data indicate that SHR3824 may suppress postprandial hyperglycemia clinically.

To demonstrate that the antihyperglycemic effects of SHR3824 were induced by its inhibitory effect on SGLT2 in vivo, the urinary glucose excretion was measured in type 2 diabetic GK rats and $d b / d b$ mice after acute administration and multiple dosing with SHR3824. The GK rat is a model of hyperglycemia and glucose intolerance while the $d b / d b$ mouse is a genetic model of type 2 diabetes that exhibits hyperglycemia, hyperinsulinemia, hyperglucagonemia and severe wholebody insulin resistance ${ }^{[26,27]}$. Both the GK rats and $d b / d b$ mice displayed increased urine volumes and glucosuria due to diabetes. The acute administration of SHR3824 dose-dependently induced a significant increase in the urine volume and urinary glucose excretion in both GK rats and $d b / d b$ mice at the minimum effective dose of $0.3 \mathrm{mg} / \mathrm{kg}$. These increases were much more apparent within the first $6 \mathrm{~h}$ rather than $6 \mathrm{~h}$ to $24 \mathrm{~h}$ postdose administration and were accompanied by an obvious decrease in blood glucose levels, demonstrating the ability of acute oral administration of SHR3824 to reduce blood glucose levels by enhancing urinary glucose excretion in diabetic rats and mice. BMS512148 showed pharmacological effects that were similar to SHR3824, consistent with previous reports using other SGLT2 inhibitors in glucose intolerant rodents, including rats fed a high-fat diet and Zucker fatty rats and mice $^{[13,28]}$.

Although previous studies have shown that the acute administration of SGLT2 inhibitors resulted in glucosuria that was accompanied by blood glucose lowering, there were few studies that evaluated the effects of multiple doses of SGLT2 inhibitors on urinary glucose excretion. In this study, we investigated the effects of SH3824 on urinary glucose excretion and blood glucose levels after $32 \mathrm{~d}$ and 13 or $40 \mathrm{~d}$ of treatment in GK rats and $d b / d b$ mice, respectively. The vehicle-treated control groups of both GK rats and $d b / d b$ mice maintained high blood glucose levels and glucosuria after chronic treatment. SHR3824 caused a significant increase in the urinary glucose excretion and a decrease in the blood glucose levels in GK rats after $32 \mathrm{~d}$ of treatment and in $d b / d b$ mice after 13 or $40 \mathrm{~d}$ of treatment. The efficacy of this treatment is similar to that observed after acute administration of SHR3824. These data suggest that SHR3824 has the ability to sustain blood glucose lowering by enhancing glucosuria after multiple dosing without causing any apparent tachyphylaxis.

Several studies have demonstrated the effectiveness of longterm SGLT2 inhibition on ameliorating metabolic disorder in diabetic animal models. Based on the increased urinary glucose excretion caused by acute or multiple administration of SHR3824 to GK rats and $d b / d b$ mice, we expected that the metabolic disorder in those diabetic rodent models would also be improved after chronic treatment. During the 41 (GK rats) or $43 \mathrm{~d}(\mathrm{db} / \mathrm{db}$ mice) of treatment with $0.3,1.0$, or $3.0 \mathrm{mg} / \mathrm{kg}$ of SHR3824, the fasting blood glucose levels in GK rats or $d b / d b$ mice were significantly lower than those of vehicle-treated control animals. Furthermore, the HbA1c levels in GK rats were also dose-dependently reduced after $38 \mathrm{~d}$ of treatment, suggesting that the hyperglycemia in these type 2 diabetic animal models can be treated by chronic administration of the SGLT2 inhibitor SHR3824. Although SGLT2 inhibitors have been demonstrated to decrease body weight in clinical studies, the chronic administration of SHR3824 affected neither the body weight nor the food intake in GK rats or $d b / d b$ mice, as reported previously by several other SGLT2 inhibitor studies $^{[13,29]}$.

Peripheral insulin resistance in patients is a major challenge of T2DM therapies. Chronic hyperglycemia aggravates insulin resistance ${ }^{[30]}$. Therefore, it is expected that a decrease in blood glucose levels could improve insulin sensitivity. Skeletal muscle is the major site for the disposal of ingested glucose, accounting for approximately $80 \%$ of the whole-body glucose disposal under insulin-stimulated conditions ${ }^{[31,32]}$. As the first rate-limiting step in skeletal muscle glucose metabolism, glucose uptake is markedly impaired under diabetic conditions ${ }^{[33]}$. A few studies have demonstrated that long-term treatment with SGLT2 inhibitors could enhance insulin sensitivity in the livers of type 2 diabetic animal models, but did not effect insulin sensitivity in muscle and adipose tissue ${ }^{[13-15]}$. In this study, a significant decrease in serum insulin levels 
was observed after chronic treatment with SHR3824 that was accompanied by decreased fasting blood glucose and HbA1c levels, suggesting that whole-body insulin sensitivity was improved. Moreover, the insulin-stimulated glucose uptake in the soleus muscle was significantly enhanced, confirming that insulin sensitivity was increased in the skeletal muscle. The improved insulin sensitivity in skeletal muscle caused by SHR3824 may be due to the long-term (6 weeks) treatment, whereas 2 weeks of treatment of ZDF rats with dapagliflozin did not significantly enhance glucose uptake in skeletal muscle in a hyperinsulinemic-euglycemic clamp study ${ }^{[13]}$.

Although glucose is the major physiological stimulator of insulin secretion and biosynthesis, extensive exposure of pancreatic $\beta$-cells to high levels of glucose in vitro causes $\beta$-cell dysfunction that is associated with impaired insulin secretion and biosynthesis ${ }^{[34]}$. Prolonged poor glycemic control in diabetic patients often leads to a decline in the insulin secretion of pancreatic $\beta$-cells and a worsening of the diabetic state $^{[35,36]}$. Thus, a great challenge in type 2 diabetes therapy is the progressive loss of $\beta$-cell mass and the deterioration of $\beta$-cell function. In this study, the immunohistochemical analyses showed reduced insulin staining in the islet cells of $d b / d b$ vehicle-treated control mice compared with lean mice, indicating a potential defect in $\beta$-cell function. Chronic treatment with SHR3824 increased insulin staining in the islet cells of $d b / d b$ mice, suggesting that $\beta$-cell function was improved. This result is similar to several other SGLT2 inhibitor studies reported previously ${ }^{[14,22]}$, and might be due to the correction of chronic hyperglycemia by enhancing urinary glucose excretion. Thus, SGLT2 inhibitors may contribute to the protection of $\beta$-cell function by suppressing glucose toxicity.

In summary, our studies demonstrate that SHR3824 is a potent and selective SGLT2 inhibitor that corrects hyperglycemia by enhancing urinary glucose excretion after acute or multiple dosing in several normal and diabetic rodent models. Chronic treatment with SHR3824 not only improves glycemic control and decreases $\mathrm{HbA1c}$ levels but also improves insulin sensitivity and restores $\beta$-cell function. These properties of SHR3824 suggest that it has the potential to be a new therapeutic agent for the treatment of type 2 diabetes. SHR3824 is currently in phase I clinical studies in China.

\section{Author contribution}

Ying LENG designed the research; Pang-ke YAN, Li-na ZHANG, Ying FENG, Hui QU, and Li QIN performed the research; Pang-ke YAN, Li-na ZHANG, and Lian-shan ZHANG analyzed the data; and Pang-ke YAN and Ying LENG wrote the paper.

\section{References}

1 Yang W, Lu J, Weng J, Jia W, Ji L, Xiao J, et al. China National Diabetes and Metabolic Disorders Study Group. Prevalence of diabetes among men and women in China. N Engl J Med 2010; 362: 1090-101.

2 Kalra S, Mukherjee JJ, Venkataraman S, Bantwal G, Shaikh S, Saboo B, et al. Hypoglycemia: the neglected complication. Indian J Endocrinol Metab 2013; 17: 819-34.
3 Wright EM. Renal $\mathrm{Na}^{+}$-glucose cotransporters. Am J Physiol Renal Physiol 2001; 280: F10-8.

4 Hediger MA, Rhoads DB. Molecular physiology of sodium-glucose cotransporters. Physiol Rev 1994; 74: 993-1026.

5 Turk E, Zabel B, Mundlos S, Wright EM. Glucose/galactose malabsorption caused by a defect in the $\mathrm{Na}^{+}$/glucose cotransporter. Nature 1991; 350: 354-6.

6 Van den Heuvel LP, Assink K, Willemsen M, Monnens L. Autosomal recessive renal glucosuria attributable to a mutation in the sodium glucose cotransporter (SGLT2). Hum Genet 2002; 111: 544-7.

7 Ehrenkranz JR, Lewis NG, Kahn CR, Roth J. Phlorizin: a review. Diabetes Metab Res Rev 2005; 21: 31-8.

8 Oku A, Ueta K, Arakawa K, Ishihara T, Nawano M, Kuronuma Y, et al. $\mathrm{T}-1095$, an inhibitor of renal $\mathrm{Na}^{+}$-glucose cotransporters, may provide a novel approach to treating diabetes. Diabetes 1999; 48: 1794800.

9 Calado J. Dapagliflozin, an oral sodium glucose cotransporter type 2 inhibitor for the treatment of type 2 diabetes mellitus. IDrugs 2009; 12: 785-98.

10 Lamos EM, Younk LM, Davis SN. Canagliflozin, an inhibitor of sodiumglucose cotransporter 2, for the treatment of type 2 diabetes mellitus. Expert Opin Drug Metab Toxicol 2013; 9: 763-75.

11 Grempler R, Thomas L, Eckhardt M, Himmelsbach F, Sauer A, Sharp DE, et al. Empagliflozin, a novel selective sodium glucose cotransporter-2 (SGLT-2) inhibitor: characterisation and comparison with other SGLT-2 inhibitors. Diabetes Obes Metab 2012; 14: 83-90.

12 Miao Z, Nucci G, Amin N, Sharma R, Mascitti V, Tugnait M, et al. Pharmacokinetics, metabolism, and excretion of the antidiabetic agent ertugliflozin (PF-04971729) in healthy male subjects. Drug Metab Dispos 2013; 41: 445-56.

13 Han S, Hagan DL, Taylor JR, Xin L, Meng W, Biller SA, et al. Dapagliflozin, a selective SGLT2 inhibitor, improves glucose homeostasis in normal and diabetic rats. Diabetes 2008; 57: 1723-9.

14 Arakawa K, Ishihara T, Oku A, Nawano M, Ueta K, Kitamura K, et al. Improved diabetic syndrome in $\mathrm{C} 57 \mathrm{BL} / \mathrm{KsJ}-\mathrm{db} / \mathrm{db}$ mice by oral administration of the $\mathrm{Na}^{+}$-glucose cotransporter inhibitor $\mathrm{T}-1095$. Br J Pharmacol 2001; 132: 578-86.

15 Thomas L, Grempler R, Eckhardt M, Himmelsbach F, Sauer A, Klein $\mathrm{T}$, et al. Long-term treatment with empagliflozin, a novel, potent and selective SGLT-2 inhibitor, improves glycaemic control and features of metabolic syndrome in diabetic rats. Diabetes Obes Metab 2012; 14 : 94-6.

16 Robertson RP, Harmon J, Tran PO, Poitout V. Beta-cell glucose toxicity, lipotoxicity, and chronic oxidative stress in type 2 diabetes. Diabetes 2004; 53: S119-24.

17 Jurczak MJ, Lee HY, Birkenfeld AL, Jornayvaz FR, Frederick DW, Pongratz RL, et al. SGLT2 deletion improves glucose homeostasis and preserves pancreatic beta-cell function. Diabetes 2011; 60: 890-8.

18 Kjorholt C, Akerfeldt MC, Biden TJ, Laybutt DR. Chronic hyperglycemia, independent of plasma lipid levels, is sufficient for the loss of beta cell differentiation and secretory function in the $d b / d b$ mouse model of diabetes. Diabetes 2005; 54: 2755-63.

19 Jonas JC, Sharma A, Hasenkamp W, Ilkova H, Patanè G, Laybutt R, et al. Chronic hyperglycemia triggers loss of pancreatic beta cell differentiation in an animal model of diabetes. J Biol Chem 1999; 274: 14112-21.

20 Rossetti L, Shulman Gl, Zawalich W, DeFronzo RA. Effect of chronic hyperglycemia on in vivo insulin secretion in partially pancreatectomized rats. J Clin Invest 1987; 80: 1037-44.

21 Liang Y, Arakawa K, Ueta K, Matsushita Y, Kuriyama C, Martin T, et al. Effect of canagliflozin on renal threshold for glucose, glycemia, and 
body weight in normal and diabetic animal models. PLoS One 2012; 7: e30555.

22 Macdonald FR, Peel JE, Jones HB, Mayers RM, Westgate L, Whaley JM, et al. The novel sodium glucose transporter 2 inhibitor dapagliflozin sustains pancreatic function and preserves islet morphology in obese, diabetic rats. Diabetes Obes Metab 2010; 12: 1004-12.

23 Wallberg-Henriksson H, Zetan N, Henriksson J. Reversibility of decreased insulin-stimulated glucose transport capacity in diabetic muscle with in vitro incubation. Insulin is not required. J Biol Chem 1987; 262: 7665-71.

24 Washburn WN. Development of the renal glucose reabsorption inhibitors: a new mechanism for the pharmacotherapy of diabetes mellitus type 2. J Med Chem 2009; 52: 1785-94.

25 Freeman JS. Review of insulin-dependent and insulin-independent agents for treating patients with type 2 diabetes mellitus and potential role for sodium-glucose co-transporter 2 inhibitors. Postgrad Med 2013; 125: 214-26.

26 Akash MS, Rehman K, Chen S. Goto-Kakizaki rats: its suitability as non-obese diabetic animal model for spontaneous type 2 diabetes mellitus. Curr Diabetes Rev 2013; 9: 387-96.

27 Herberg L, Leiter EH. Obesity/diabetes in mice with mutations in the leptin or leptin receptor genes. In: Shima, AAF, Shafrir, E (Eds), Animal Models of Diabetes A Primer. Harwood academic publishers, Amsterdam, 2001. pp 63-107.

28 Fujimori Y, Katsuno K, Nakashima I, Ishikawa-Takemura Y, Fujikura $\mathrm{H}$, Isaji M. Remogliflozin etabonate, in a novel category of selective low-affinity sodium glucose cotransporter (SGLT2) inhibitors, exhibits antidiabetic efficacy in rodent models. J Pharmacol Exp Ther 2008; 327: 268-76.

29 Fujimori Y, Katsuno K, Ojima K, Nakashima I, Nakano S, IshikawaTakemura Y, et al. Sergliflozin etabonate, a selective SGLT2 inhibitor, improves glycemic control in streptozotocin-induced diabetic rats and Zucker fatty rats. Eur J Pharmacol 2009; 609: 148-54.

30 Araújo TG, Oliveira AG, Saad MJ. Insulin-resistance-associated compensatory mechanisms of pancreatic beta cells: a current opinion. Front Endocrinol (Lausanne) 2013; 4: 146.

31 DeFronzo RA, Tripathy D. Skeletal muscle insulin resistance is the primary defect in type 2 diabetes. Diabetes Care. 2009; 32: S15763.

32 DeFronzo RA. The triumvirate: beta-cell, muscle, liver. A collusion responsible for NIDDM. Diabetes 1988; 37: 667-87.

33 Tsao TS, Burcelin R, Charron MJ. Regulation of hexokinase II gene expression by glucose flux in skeletal muscle. J Biol Chem 1996; 271 : 14959-63.

34 Robertson RP, Zhang HJ, Pyzdrowski KL, Walseth TF. Preservation of insulin mRNA levels and insulin secretion in HIT cells by avoidance of chronic exposure to high glucose concentrations. J Clin Invest 1992; 90: 320-5.

35 Rossetti L. Glucose toxicity: the implications of hyperglycemia in the pathophysiology of diabetes mellitus. Clin Invest Med 1995; 18 : 255-60.

36 Mooradian AD, Thurman JE. Glucotoxicity: potential mechanisms. Clin Geriatr Med 1999; 15: 255. 